\title{
Reconstitution of the Electron Transport System That Couples Formate Oxidation to Nitrogenase in Methylosinus trichosporium OB3b
}

\author{
By YUNG-PIN CHEN AND DUANE C. YOCH* \\ Department of Biology, University of South Carolina, Columbia, South Carolina 29208, USA
}

(Received 27 April 1988; revised 27 July 1988)

\begin{abstract}
The electron transfer system that transports electrons from formate to nitrogenase was examined in extracts of the obligate methanotroph Methylosinus trichosporium OB3b. By supplementing a crude nitrogenase extract with NAD, formate dehydrogenase, NADHferredoxin reductase and FMN (an FDH cofactor), an electron transport system was established that coupled formate oxidation to nitrogenase-dependent acetylene reduction. The ferredoxin dependence of this reaction was demonstrated by its severe inhibition by antibodies to ferredoxin. The reaction sequence is as follows: formate $\rightarrow$ formate dehydrogenase $\rightarrow$ NADH $\rightarrow$ NADH-ferredoxin reductase $\rightarrow$ ferredoxin $\rightarrow$ nitrogenase.
\end{abstract}

\section{INTRODUCTION}

Methanotrophs can use methane and the intermediates of methane oxidation as energy sources for $\mathrm{N}_{2}$ fixation (Dalton \& Whittenbury, 1976; Toukdarian \& Lidstrom, 1984), but it is not known how the oxidation of these one-carbon intermediates is coupled to the reduction of nitrogenase. With approximately $70 \%$ of the $\mathrm{O}_{2}$-uptake used for the initial $\mathrm{C}_{1}$ hydroxylation reaction (Anthony, 1982a), there appears to be relatively little reductant (NADH) available for the necessary biosynthetic reactions, much less for the reduction of $\mathbf{N}_{2}$. Based on our current knowledge of these organisms, the demands for NADH, especially when the organism is fixing $\mathbf{N}_{2}$, would seem to be greater than its supply. However, no alternative reductant seems to be available to the cells.

With NADH as its only known source of reducing power, the reduction of the nitrogenase (via a ferredoxin) would be difficult to achieve in Methylosinus trichosporium because most ferredoxins require a reductant with an oxidation-reduction potential of about $-400 \mathrm{mV}$ (Yoch \& Carithers, 1979). Since all the electron transport processes that have been reported for this group of micro-organisms involve electron carriers whose redox potentials $\left(E_{0}^{*}\right)$ are positive (Anthony, 1982b), it would suggest that $\mathrm{N}_{2}$-fixing methanotrophs must have an additional redox system capable of transporting low potential electrons. By analogy with other $\mathbf{N}_{\mathbf{2}}$-fixing bacteria such a system would be expected to involve ferredoxins or flavodoxins that would either be reduced directly by a dehydrogenase, or by an NADH-linked oxidoreductase. While not excluding the first possibility, recent data from our laboratory have shown that the reduction of an endogenous ferredoxin from $M$. trichosporium $\mathrm{OB} 3 \mathrm{~b}$ could be coupled to formate oxidation by a reaction that requires an NAD-linked formate dehydrogenase and a newly discovered NADH-ferredoxin reductase (unpublished results).

In this communication we report the in vitro reconstitution of an electron transport system which couples formate oxidation to acetylene reduction by nitrogenase in $M$. trichosporium OB3b.

Abbreviations: FDH, formate dehydrogenase; NFR, NADH-ferredoxin reductase. 


\section{METHODS}

Organism and growth. Methylosinus trichosporium OB3b (obtained from Dr Mary Lidstrom) was cultured in 500 $\mathrm{ml}$ media in 2 litre Erlenmeyer flasks shaken at 200 r.p.m. in a Lab-Line Orbit Shaker at $29^{\circ} \mathrm{C}$. The medium used for nitrogenase derepressed cultures was that of Dalton \& Whittenbury (1976), modified by lowering the nitrate concentration to $2.5 \mathrm{mM}$. After $3 \mathrm{~d}$, the culture turbidity was about $70 \mathrm{Klett}$ units; at this point the nitrate was depleted and nitrogenase was derepressed. For the preparation of formate dehydrogenase and NADH-ferredoxin reductase, cells were grown on nif-repressing concentrations of nitrate $(20 \mathrm{~mm})$. The cultures were evacuated and regassed each day with an air/methane mixture $(1: 1, \mathrm{v} / \mathrm{v})$.

Cell-free extracts. These were prepared from cells harvested anaerobically by resuspending the cell pellets (under a flow of Ar) in 2 vols Ar-saturated $300 \mathrm{~mm}$-Tricine buffer, $\mathrm{pH} 7.8$. The cell suspension was placed in a bottle fitted with a serum stopper, which was evacuated for 5 min then refilled with Ar depleted of $\mathrm{O}_{2}$ by passing it through a column of hot, $\mathbf{H}_{2}$-activated BASF catalyst $\mathbf{R 3}-11$. After the cells were cooled to $3^{\circ} \mathrm{C}$ on ice, they were transferred to an anaerobic sonication vessel for disruption as described previously (Chen \& Yoch, 1987). The extract was centrifuged at $27000 \mathrm{~g}$ for $30 \mathrm{~min}$ and the supernatant was removed anaerobically by syringe and placed in a degassed stoppered bottle. This crude nitrogenase extract was used in the experiments described below.

$N A D H$-ferredoxin reductase (NFR). This was isolated from either nitrogenase repressed or derepressed $M$. trichosporium cultures by passing the crude extract (prepared as above) across a bed of DE-52 cellulose $(2 \times 10 \mathrm{~cm})$ equilibrated with degassed $50 \mathrm{~mm} / \mathrm{Tris} / \mathrm{HCl}$ buffer, $\mathrm{pH} 7 \cdot 0$. After washing the column with $30 \mathrm{ml}$ of this buffer, NFR was eluted with buffer containing $0 \cdot 1 \mathrm{M}-\mathrm{NaCl}$. Fractions with activity were pooled and chromatographed on a Sephadex G-100 column $(0.9 \times 50 \mathrm{~cm})$ eluted with $50 \mathrm{mM}$-Tris $/ \mathrm{HCl}$ buffer. The assay for NFR utilized spinach ferredoxin and consisted of measuring ferredoxin-dependent electron transport from NADH to horse heart cytochrome $c$ (Yoch, 1973). Cytochrome $c$, which is reduced non-enzymically by reduced ferredoxin, was monitored by an increase in absorbance at $550 \mathrm{~nm}$.

Formate dehydrogenase (FDH). This was eluted from the DE-52 cellulose column described above when the $\mathrm{NaCl}$ concentration in the buffer was increased to $0.2 \mathrm{M}$. Fractions $(1 \mathrm{ml})$ were collected anaerobically in Eppendorf tubes which were then stoppered, evacuated and refilled with Ar. All samples, whether further purified or not, were stored on ice until used. Activity was stable for at least 2 weeks under these conditions. FDH was further purified by passage over an anaerobic Sephadex G-100 column $(0.9 \times 50 \mathrm{~cm})$ eluted with the Tris buffer. Formate dehydrogenase was assayed in a reaction mixture containing $40 \mathrm{mM}-\mathrm{Tris} / \mathrm{HCl}$ (or potassium phosphate) buffer, pH 7.0, $10 \mathrm{~mm}$-sodium formate, $2 \mathrm{mM}-\mathrm{NAD}$ and $2.5 \mu \mathrm{M}-\mathrm{FMN}$. A cuvette with the reaction mixture was closed with a serum stopper; it was evacuated and regassed three or four times with Ar through a syringe needle. The reaction was started by adding FDH anaerobically by syringe. The reduction of NAD was monitored by its increase in absorbance at $340 \mathrm{~nm}$.

Nitrogenase activity. This was measured in cell-free extracts in $5 \mathrm{ml}$ Fernbach flasks. The complete reaction mixture contained, in a final volume of $1.5 \mathrm{ml}: 50 \mathrm{mM} H E P E S / \mathrm{NaOH}$ buffer, $\mathrm{pH} 7.4,24 \mathrm{~mm}$-phosphocreatine, $20 \mu \mathrm{g}$ creatine phosphokinase, $15 \mathrm{mM}-\mathrm{MgCl}_{2}$ and $2.9 \mathrm{~mm}$-ATP. The reductant was either $33 \mathrm{~mm}$-sodium dithionite (the control) or 10 mu-sodium formate. Acetylene was added to each flask to a final concentration of $5 \%(v / v)$. Additional details of the formate-driven nitrogenase reaction are given in the legend to Table 1 . Nitrogenase activity was measured by the reduction of acetylene to ethylene over a $15 \mathrm{~min}$ period. These two gases were separated on an alumina column eluted with $\mathrm{N}_{2}$ at $195^{\circ} \mathrm{C}$, and detected by gas chromatography with a flame ionization detector. Peaks were integrated on an HP 3390 (Hewlett-Packard) integrator.

Ferredoxin antiserum. This was obtained by vaccinating a male New Zealand white rabbit three times over a 6 week period with approximately $100 \mu \mathrm{g}$ pure Rhodospirillum rubrum ferredoxin II (in the native state) plus incomplete adjuvant. The antibody $(\mathrm{IgG})$ fraction was isolated as the 0 to $50 \%$ ammonium sulfate precipitate. This precipitation was repeated on the resolubilized immunoglobulin fraction which was then dialysed extensively against $0.9 \% \mathrm{NaCl}$, and frozen as individual samples until needed.

\section{RESULTS}

When $M$. trichosporium is grown on methane under nitrogen-limited conditions, nitrogenase is derepressed. Such cells oxidize formate by a constitutive FDH for the generation of both the ATP and the reductant needed for nitrogenase (acetylene reduction) activity. The concentration of formate which supported maximal rates of activity was between 10 and $15 \mathrm{mM}$, with severe inhibition beyond this concentration (Fig. 1). We have previously shown that under these same culture conditions a constitutive hydrogenase will also support nitrogenase activity (Chen \& Yoch, 1987).

Cell-free extracts prepared from nitrogen-limited cells had nitrogenase activity when dithionite was used as a direct reductant of the Fe protein and an ATP-regenerating system was 


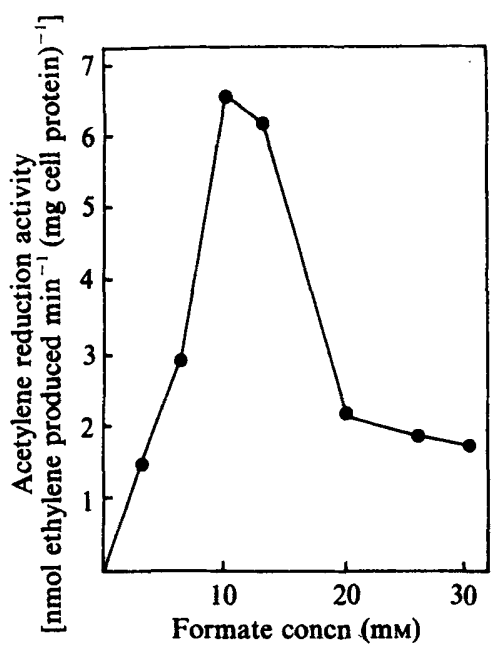

Fig. 1. Formate-dependent acetylene reduction activity by $M$. trichosporium $\mathrm{OB} 3 \mathrm{~b}$. Cells for this experiment were grown on methane and a limiting concentration of nitrate to derepress nitrogenase.

Table 1. In vitro reconstitution of formate-dependent nitrogenase activity

The complete reaction mixture contained $1.65 \mathrm{mg}$ crude extract protein, $2 \mathrm{mM}-\mathrm{NAD}, 10 \mathrm{mM}$-formate, $6 \mu \mathrm{M}-\mathrm{FMN}, 9 \mu \mathrm{g}$ NFR and $15 \mu \mathrm{g}$ FDH. The ATP-regenerating system and the general techniques for the nitrogenase assay are described in Methods.

$\begin{array}{lc}\begin{array}{c}\text { Reaction } \\ \text { mixture }\end{array} & \begin{array}{c}\text { Acetylene reduction activity } \\ \text { [nmol ethylene produced min } \\ \text { (mg protein) }\end{array} \\ \text { Plus dithionite (control) }\end{array}$

provided (Table 1). When formate and NAD were substituted for dithionite, however, no activity was observed. It was only when the nitrogenase extracts were also supplemented with formate dehydrogenase and NADH-ferredoxin reductase (NFR) that any activity was observed with formate. NAD reduction by formate dehydrogenase was stimulated by FMN (data not shown), and since electron transport to nitrogenase appeared to proceed through NADH, we added $6 \mu \mathrm{M}$-FMN to the reaction mixture. The addition of FMN stimulated this reconstituted system 5-fold. The acetylene reduction activity of the complete formate-driven reconstituted system was equivalent to that supported by dithionite (Table 1).

The response of formate-driven acetylene reduction activity to increased concentrations of NFR and FDH is seen in Fig. 2(a) and Fig. 2(b), respectively. These proteins were used directly from the initial DE-52 cellulose column, so the protein concentrations are quite high. While NFR was not saturating in this experiment, maximal acetylene reduction was observed between 60 and $75 \mu \mathrm{g}$ NFR protein in another experiment.

The ferredoxin requirement for formate-dependent acetylene reduction is not seen in Table 1 because its concentration in crude extracts was sufficient for maximal nitrogenase activity. An indirect means was used to demonstrate the involvement of an endogenous ferredoxin in the 


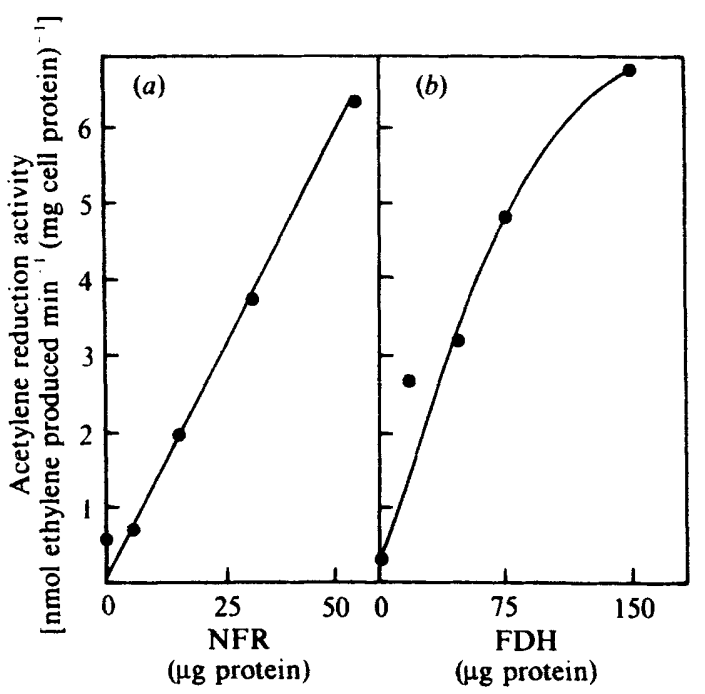

Fig. 2. Effect of NFR $(a)$ and FDH $(b)$ concentration on formate-driven nitrogenase activity in $M$. trichosporium. The reaction components are described in the legend to Table 1, with NFR and FDH added as indicated.

A

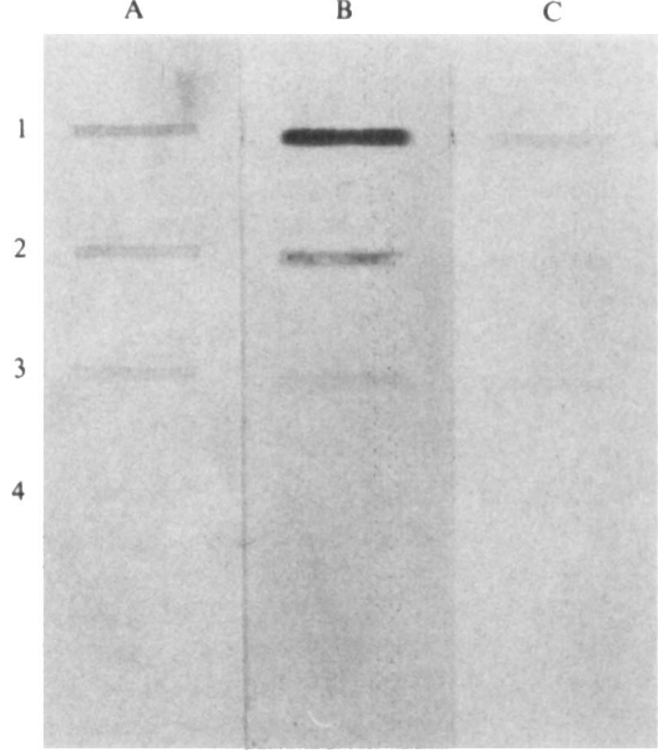

Fig. 3. Immunoblots showing cross-reactivity of $M$. trichosporium ferredoxin with antiserum against $R$. rubrum ferredoxin II. Lane A, $M$. trichosporium ferredoxin fraction; blots $1-4,6.6,3 \cdot 3,1 \cdot 3$ and $0.3 \mu \mathrm{g}$ protein, respectively. Lane B, $R$. rubrum ferredoxin II; blots $1-4,8.0,4.0,1.6$ and $0.4 \mu \mathrm{g}$ protein, respectively. Lane C, $R$. mubrum ferredoxin I; blots $1-4,7.5,3.25,1.3$ and $0.325 \mu \mathrm{g}$ protein, respectively. All proteins were applied in the native state.

formate-driven nitrogenase reaction. After demonstrating that antibody to $R$. rubrum ferredoxin II shows measurable specificity toward the $M$. trichosporium Fd (Fig. 3, lane A) compared to a positive control (lane B) and a negative control (lane $\mathrm{C}$ ), the antibody was added in increasing concentrations to the complete formate-driven nitrogenase reaction mixture. The results show 


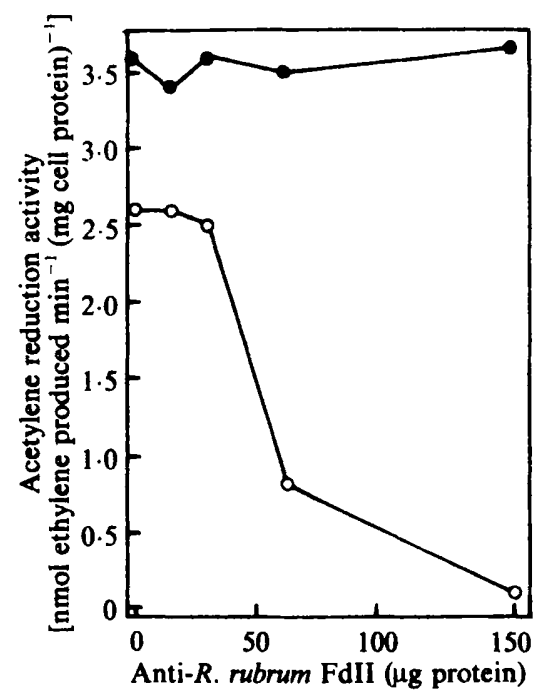

Fig. 4. Inhibitory effect of ferredoxin antibody on formate-dependent nitrogenase activity in extracts of $M$. trichosporium. Antibody prepared against $R$. rubrum ferredoxin II was added at increasing concentrations to extracts in which dithionite was the electron donor $(O)$ and to 'complete' reaction mixtures, as described in Table 1 , in which formate was the electron donor $(O)$. The crude extract in the complete reaction mixture contained $0.66 \mathrm{mg}$ protein; there was $180 \mu \mathrm{g}$ (protein) FDH and $60 \mu \mathrm{g}$ NFR per vessel.

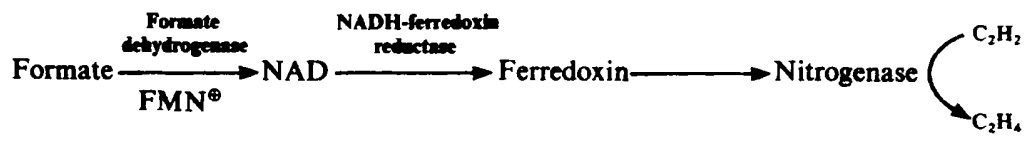

Fig. 5. Reaction sequence coupling electron transport from formate to nitrogenase by $M$. trichosporium.

that acetylene reduction activity was progressively inhibited as the antibody level was increased which suggests a role for ferredoxin in this reaction (Fig. 4). The control shows that when the antibody to ferredoxin was added to the dithionite-dependent reaction mixture, there was no effect since dithionite reduces the nitrogenase Fe protein directly. This indirect evidence for ferredoxin involvement in the formate-driven reaction is reinforced by the fact that the only way NFR could contribute to this activity (Table 1) would be if a ferredoxin was involved. The reaction scheme showing the coupling of formate oxidation to nitrogenase acetylene reduction is seen in Fig. 5.

\section{DISCUSSION}

The limited amount of reductant that $M$. trichosporium seems to have available for biosynthesis may manifest itself in its low in vivo rates of $\mathrm{N}_{2}$-fixation. Formate-dependent acetylene reduction activity ranges from 5 to $10 \mathrm{nmol} \mathrm{C}_{2} \mathrm{H}_{4}$ formed min $^{-1}$ (mg cell protein) ${ }^{-1}$ (Dalton \& Whittenbury, 1976; Dalton, 1980; Toukdarian \& Lidstrom, 1984), compared to

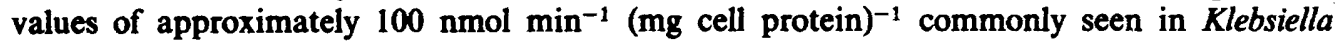
pneumoniae (Shanmugam et al., 1975). In vitro, where reductant and ATP could be provided in excess, the specific activity of Methylosinus nitrogenase was still lower than that of Klebsiella, but 
our finding that NADH-supported nitrogenase activity was equivalent to that supported by dithionite was surprising in light of the low rates achieved with NADH (compared to those supported by dithionite) in cell extracts of other aerobic $\mathbf{N}_{2}$-fixers (Klucas \& Evans, 1968; Yates \& Daniel, 1970; Beneinann et al., 1971).

The problem of reducing nitrogenase with NADH is really one of reducing ferredoxin. The reduction of a ferredoxin with an $E_{0}^{\prime}$ of $-420 \mathrm{mV}$ from NADH is thermodynamically unfavourable $\left(\Delta G^{\prime \prime}=+18 \mathrm{~kJ} \mathrm{~mol}^{-1}\right)$. This endothermic reaction becomes feasible only if the ferredoxin remains primarily in an oxidized state by being rapidly re-oxidized after it is reduced. This situation exists in cells containing nitrogenase and an excess of ATP. In vitro this reaction also requires, in addition to ATP, an enzyme that facilitates the efficient transfer of electrons from NADH to ferredoxin. With the discovery and purification of NFR in $M$. trichosporium (unpublished results) this enzyme could be added to the crude extract to enhance ferredoxin reduction. Without an exogenous source of this enzyme, NADH-supported nitrogenase activity in Azotobacter vinelandii (Yates \& Daniel, 1970; Benemann et al., 1971) and Rhizobium bacteroids (Klucas \& Evans, 1968) is extremely low. In Clostridium pasteurianum, which has a stable, functional NFR, nitrogenase activity supported by NADH is about $25 \%$ of that supported by dithionite (Jungermann et al., 1974).

In summary an electron transport pathway has been reconstituted that supports significant levels of acetylene reduction from FDH, NFR and an endogenous ferredoxin.

This work was supported by a grant from the National Science Foundation (no. DMB-8419927).

\section{REFERENCES}

ANTHONY, C. (1982a). The Biochemistry of Methylotrophs. London: Academic Press.

ANTHONY, C. (1982b). Bacterial oxidation of methane and methanol. Advances in Microbial Physiology 27, 113-210.

Bengarann, J. R., Yoch, D. C., Valentine, R. C. \& ARNON, D. I. (1971). The electron transport system in nitrogen fixation by Azotobacter. III. Requirements for NADPH-supported nitrogenase activity. Biochimica et biophysica acta 226, 205-212.

Cribn, Y.-P. \& YoCH, D. C. (1987). Regulation of two nickel-requiring (inducible and constitutive) hydrogenase and their coupling to nitrogenase in Methylosinus trichosporium OB3b. Jowmal of Bacteriology 169, 4778-4783.

DAlToN, H. (1980). Chemoautotrophic nitrogen fixation. In Proceedings of the Phytochemical Society of Europe Symposium, vol. 18, pp. 177-196. Edited by W. D. P. Stewart \& J. R. Gallon. London: Academic Press.

Dalton, H. \& WhItTBNBURY, R. (1976). The acetylene reduction techniques as an assay for nitrogenase activity in the methane oxidizing bacterium. Methylococcus capsulatus strain Bath. Archives of Microbiology 109, 147-151.

Jungermann, K., Krrchniawy, H., Katz, N. \&
ThAUER, R. K. (1974). NADH, a physiological electron donor in clostridial nitrogen fixation. FEMS Letters 43, 203-206.

KiUCAs, R. V. \& Evans, H. J. (1968). An electron donor system for nitrogenase-dependent acetylene reduction by extracts of soybean nodules. Plant Physiology 43, 1458-1460.

ShammugaM, K. T., Chan, I. \& Morand, C. (1975). Regulation of nitrogen fixation. Nitrogenasederepressed mutants of Klebsiella pneumoniae. Biochemica et biophysica acta 408, 101-111.

TOURDARIAN, A. E. \& LIDSTROM, M. E. (1984). Nitrogen metabolism in a new obligate methanotroph, Methylosinus strain 6. Journal of General Microbiology 130, 1827-1837.

YATES, M. G. \& DANIEL, R. M. (1970). Acetylene reduction with physiological electron donors by extracts and particulate fractions from nitrogenfixing Azotobacter chroococcum. Biochimica et biophysica acta 197, 161-169.

YOCH, D. C. (1973). Purification and characterization of ferredoxin-nicotinamide dinucleotide phosphate reductase from a nitrogen-fixing bacterium. Journal of Bacteriology 116, 384-391.

YOCH, D. C. \& CARITHERS, R. P. (1979). Bacterial nonsulfur proteins. Microbiological Reviews 43, 384-421. 